\title{
Patient perceptions of the benefits and barriers of virtual postnatal care: a qualitative study
}

\author{
Megan Saad', Sophy Chan², Lisa Nguyen², Siddhartha Srivastava ${ }^{2}$ and Ramana Appireddy²*
}

\begin{abstract}
Objective: The objective of this study is to understand the perceptions of new mothers using virtual care via video conferencing to gain insight into the benefits and barriers of virtual care for obstetric patients.

Methods: Semi-structured interviews were conducted with 15 patients attending the Kingston Health Sciences Centre. The interviews were 20-25 min in length and recorded through an audio recorder. Thematic analysis was conducted in order to derive the major themes explored in this study.
\end{abstract}

Results: New mothers must often adopt new routines to balance their needs and their child's needs. These routines could impact compliance and motivation to attend follow-up care. In our study, participants expressed high satisfaction with virtual care, emphasizing benefits related to comfort, convenience, communication, socioeconomic factors, and the ease of technology use. Participants also perceived that they could receive emotional support and build trust with their health care providers despite the remote nature of their care. Due to its ease of use and increased accessibility, we argue that virtual care shows promise to facilitate long-term compliance to care in obstetric patients.

Conclusions: Virtual care is a useful modality that could improve compliance to obstetric care. Further research and clinical endeavours should examine how social factors and determinants intersect to determine how they underpin patient perceptions of virtual and in-person care.

Keywords: Telemedicine, Postpartum Period, Postnatal Care, Qualitative Research, Social Determinants of Health

\section{Introduction}

A significant proportion of women experience medical complications such as hypertension and diabetes in the postpartum period [1, 2]. Many of these conditions require and benefit from ongoing medical care, as longterm prognosis could lead to an elevated risk of cardiovascular disease and mortality [1-3]. Hypertensive disorders and gestational diabetes have been associated with a $50-300 \%$ increase in risk for cardiovascular disease $[4,5]$. A multitude of factors related to pregnancy

\footnotetext{
*Correspondence: mrra@queensu.ca

2 Department of Medicine, Queen's University, Kingston, ON, Canada

Full list of author information is available at the end of the article
}

and associated medical complications can significantly affect the quality of life of new mothers [6-9]. Thus, clinical intervention in the postpartum period is significant in reducing maternal morbidity and increasing quality of life. However, the burden and demands of dealing with pregnancy and the post-partum period along with the pre-existing barriers (socio-demographic and geographical) in accessing health care can negatively impact patient compliance in attending postnatal follow-up clinics $[10,11]$. Telemedicine can improve accessibility to postnatal healthcare services for this unique patient population and thus enhance patient care [12, 13]. Virtual care allows patients to consult with their healthcare provider through digital technologies. Virtual care can 
be conducted through various modalities, such as email, text messaging, or audio-videoconferencing and through personal digital devices, such as a smartphone or tablet, without any additional infrastructure required [14-16].

The World Health Organization defines the social determinants of health as the conditions in which people are born, grow, work, live, and age, and the wider set of forces and systems shaping the conditions of daily life [17]. The Social Determinants of Health (SDoH) framework posits that biological outcomes and access to health care are mediated by social inequalities [18]. In particular, gender uniquely intersects with other social and environmental determinants. As such, new mothers are often burdened by a unique set of challenges and can be disproportionately limited in their access to health care. Immigration status, language proficiency, Aboriginal status, food insecurity, poverty and rurality are known determinants that make it difficult for mothers to obtain the care they need [19]. However, the SDoH may uniquely impact health and healthcare access for new mothers given that considerations around accessibility may be different. Therefore, the objective of this study was to understand the perspectives of new mothers using virtual visits for postnatal follow-up care to gain insight into benefits and barriers of virtual care for obstetric patients. These insights can elucidate whether virtual care can address challenges related to health care access.

\section{Methods}

\section{Study Design}

This paper draws on a case study research design. A case study approach allows for an in-depth exploration of complex issues or a phenomenon in a given context and explores the multiple aspects of a phenomenon through the perspectives, descriptions, and lived experiences of the persons impacted by the issue or phenomenon at hand [20,21]. The SAGE Encyclopedia of Qualitative Research defines perception as "a mode of apprehending reality and experience through the senses" [22]. Researchers capture perspectives through narratives that detail life experiences, behaviours, and reactions. Through an in-depth analysis of perceptions, researchers can understand how different factors determine an individual's experiences of a phenomena. Thus, we are using a case study research design to provide readers with a generalizable, but also complex, portrayal of how patients experience and perceive virtual care in an obstetric context. By asking participants about their experiences with postnatal virtual care, we sought to elucidate the perceptions of participants as to the benefits and barriers of this modality of care compared to traditional in person visits.

To capture these nuanced perspectives, we conducted semi-structured interviews with patients being seen at the Kingston Health Sciences Centre (KHSC) for maternal postnatal follow-up virtual visits with an obstetric medicine physician. The purpose of semi-structured interviews is to guide interviewees to speak openly about their experiences and perspectives accessing postnatal virtual follow-up healthcare appointments without any pre-set answers [23]. The open-ended nature of the questions also let participants to draw on different aspects of their experiences to inform their perspectives.

\section{Research Setting}

The Kingston Health Sciences Centre (KHSC) is the largest acute-care academic hospital in south-eastern Ontario, the most populated province in Canada. The KHSC consists of the Kingston General Hospital and Hotel Dieu Hospital and sees over 500,000 patients from the region. The obstetrics program at KHSC is carried out at the Kingston General Hospital and is the largest obstetrics program in southeastern Ontario. The obstetric care team supports childbearing persons with outpatient care and provides educational services to support child-bearing persons, particularly individuals presenting with comorbidities, throughout and following pregnancy. The research team is comprised of a medical student, two obstetric medicine physicians, and two virtual care researchers who seek to better understand and improve the virtual care experience for all patients. To prevent bias, only the medical student and researcher members conducted interviews with the participants. The obstetric physician members recruited the participants and provided crucial context for the project.

\section{Sampling Strategy}

The research team employed a purposive sampling strategy. New mothers who completed at least one virtual visit appointment at the Kingston General Hospital were invited to participate in the study. This was determined by the obstetric physician member on our study team. All prospective participants were required to speak conversational English and be over the age of 18. The virtual visits, conducted via video conferencing, were hosted through the Ontario Telemedicine Network (OTN) [24]. A medical secretary and two members of the research team invited all the participants to the study by telephone. A Letter of Information was sent through email to all interested participants. In the Letter of Information, the participants were let known that the research team sought to improve patient experience using virtual care and to understand their perspectives of receiving health care through virtual care. 


\section{Data Collection}

Thirty-one patients who completed a virtual visit appointment between February and August 2020 were invited to participate in this study [23]. A medical secretary invited all potential participants by telephone. Two study team members (S.C. and M.S.), a research associate and a medical student, conducted the telephone interviews. The interview tool was developed in English drawing on similar survey tools, relevant literature, and patient-oriented interview guides employed by our team in previous projects. Due to the COVID-19 pandemic, the interviews were conducted over the telephone and recorded using an audio recorder. With sensitivity to the participant's availability, all interviews lasted 20-25 min. The interviews were aimed to be kept short and concise considering the participant demographic, as all of the interviewees were new mothers who had just recently given birth and were concurrently caring for their children at the time of the interviews. Further, many of our participants only agreed to participate in the study if the interview timeframe was relatively short due to the need to look after their dependents. Field notes were taken during the interviews.

\section{Data Analysis}

The interviews were transcribed verbatim by a hired transcriptionist, and the transcripts coded by S.C. and M.S. The data was coded using NVivo 12.0. Braun and Clarke's thematic analysis approach was used throughout the coding process for identifying, analyzing and reporting patterns within the data [25]. Consensus of the coding themes was reached through an iterative process, where S.C. and M.S. came together at every $5^{\text {th }}$ stage of the coding process to review and refine the parent themes and subthemes.

We determined that saturation was achieved when 1) the same themes were repeated by participants, 2) no new themes emerged from the data, and 3) when no other eligible individuals could be recruited within the study period. All individuals who fit the eligibility criteria and were seen by obstetric physician team members on this project between March and August 2020 were contacted to participate in this study. This time period was chosen to ensure that only new mothers up to 4-months post-partum could participate in this study.

\section{Results}

Out of thirty-one potential participants, fifteen participants were interviewed from July-August 2020. Six patients declined to participate in the study. Nine participants signed up to participate but did not end up completing the interview following multiple attempts at follow-up. It was decided to recruit and interview a limited number of participants to maintain a strong level of rigor in the data collection and analysis. The ages of participants ranged from 22 to 41 years. All participants identified as female, and majority of participants were married, Canadian-born and of white/Caucasian ethnicity. A majority of participants were also employed in some capacity, living in Kingston, ON, and had a bachelor's degree or above (Table 1). Details on travel distance, travel time, number of virtual care visits, and the medical profiles of the participants are listed in Table 2.

As per the objective of the study to understand the perceptions of new mothers using virtual care, we identified two major themes: benefits and challenges of using virtual care (Fig. 1). We found three subthemes under the theme of "benefits": increased comfort and convenience; relieving emotional and financial stress; and facilitating emotional support and rapport with the physician (Fig. 2). Participants perceived that lack of familiarity with technology use was a major barrier to virtual care use.

\section{Benefits of Using Virtual Care Increased comfort and convenience}

Across the interviews, participants spoke broadly about their mothering experiences. Many participants spoke specifically to the challenges of being a new mother and changes they have adopted to their daily lives since having a child. Some of the changes included having to prioritize their child's needs, adopting new routines, and balancing multiple conflicting priorities. Challenges associated with these changes included scheduling difficulties for healthcare appointments or other daily activities, increased demands for planning and arranging the day, difficulty breastfeeding, time constraints associated with a busier lifestyle, and the overall burden of care on new mothers. Table 2 documents the travel time and distance that our participants had to take to participate in the in-person clinic. The mean travel time for all participants to drive from their home to the hospital and back to their home was $78.3 \mathrm{~min}$. Participants would spend much more time travelling if they had multiple visits.

Participants perceived that virtual care facilitated comfort and convenience which included the ability to stay at home to conduct the call and to work around the schedule of the participants. Many participants perceived that virtual care could be a useful modality as it provided patients an opportunity to receive care while balancing the domestic tasks of new mothers. Some of these tasks included working around their child's eating and sleeping schedule, accommodating for the schedules of multiple children in the household, or working around the schedules of their caregivers or family members. 
Table 1 Sociodemographic data of all participants $(n=15)$

\begin{tabular}{|c|c|c|}
\hline Variable & Values & Number (\%) \\
\hline \multirow[t]{5}{*}{ Age categories } & $20-24$ & $1(7 \%)$ \\
\hline & $25-29$ & $2(13 \%)$ \\
\hline & $30-34$ & $6(40 \%)$ \\
\hline & $35-39$ & $4(27 \%)$ \\
\hline & $40-44$ & $2(13 \%)$ \\
\hline \multirow[t]{2}{*}{ Gender } & Female & $15(100 \%)$ \\
\hline & Male & $0(0 \%)$ \\
\hline \multirow[t]{6}{*}{ Ethnicity } & White/Caucasian & $8(53 \%)$ \\
\hline & South Asian & $1(7 \%)$ \\
\hline & African & $1(7 \%)$ \\
\hline & Portuguese & $1(7 \%)$ \\
\hline & Arab & $1(7 \%)$ \\
\hline & Unknown & $3(20 \%)$ \\
\hline \multirow[t]{7}{*}{ Employment } & Healthcare Sector & $6(40 \%)$ \\
\hline & Education Sector & $2(13 \%)$ \\
\hline & Administration & $2(13 \%)$ \\
\hline & Creative Professional & $1(7 \%)$ \\
\hline & Student & $1(7 \%)$ \\
\hline & Unemployed & $1(7 \%)$ \\
\hline & Unknown & $2(13 \%)$ \\
\hline \multirow[t]{6}{*}{ Education } & High School & $1(7 \%)$ \\
\hline & College Diploma & $2(13 \%)$ \\
\hline & Bachelor's Degree & $6(40 \%)$ \\
\hline & Master's Degree & $2(13 \%)$ \\
\hline & $\mathrm{PhD}$ & $1(7 \%)$ \\
\hline & Unknown & $3(20 \%)$ \\
\hline \multirow[t]{3}{*}{ Place of Residence } & Urban (in Kingston, ON) & $5(33 \%)$ \\
\hline & Urban (Outside Kingston, ON) & $4(27 \%)$ \\
\hline & Rural (Outside Kingston, ON) & $6(40 \%)$ \\
\hline \multirow[t]{7}{*}{ Household Income } & $\$ 0$ to $\$ 30,000$ & $3(20 \%)$ \\
\hline & $\$ 30,000$ to $\$ 59,999$ & $2(13 \%)$ \\
\hline & $\$ 60,000$ to $\$ 89,999$ & $3(20 \%)$ \\
\hline & $\$ 90,000$ to $\$ 119,999$ & $3(20 \%)$ \\
\hline & $\$ 120,000$ to $\$ 149,999$ & $0(0 \%)$ \\
\hline & $\$ 150,000$ or more & $1(7 \%)$ \\
\hline & Unknown & $3(20 \%)$ \\
\hline \multirow[t]{3}{*}{ Marital Status } & Married & $13(87 \%)$ \\
\hline & Unmarried (in a relationship) & $1(7 \%)$ \\
\hline & Unmarried (single) & $1(7 \%)$ \\
\hline \multirow[t]{3}{*}{ Immigrant Status } & Canadian-Born & $9(60 \%)$ \\
\hline & Non-Canadian Born & $3(20 \%)$ \\
\hline & Unknown & $3(20 \%)$ \\
\hline
\end{tabular}

Further, participants with co-morbidities such as chronic migraines and irritable bowel disorder could make it difficult to travel long distances. All participants reflected positively on their experiences with virtual care:

It's great because I don't have to worry about getting ready and making child care arrangements. I can just put my son in the chair next to me and it makes it far more accessible. Neither of us has to take time off work really (P3, aged 34).

It made it a lot easier 'cause it was a lot less time consuming, not having to pack up and go out. I can even do it while the baby was napping and not have to mess up their schedule, like, kids' schedules. It was a lot easier (P4, aged 34).

I found it much easier to just be able to be at home, not have to worry about getting the kids ready and long care rides or have to worry about findings someone to watch them. They were very good if I needed to take care of the baby for a second or breastfeed. There's a lot you do (P9, aged 28).

\section{Relieving stress associated with in-person care}

Participants identified that travel time, distance, finding parking, and cost were barriers to attending in-person obstetric care, leading to undue stress. Participants perceived that virtual care could be a useful modality to relieve financial and emotional stress related to attending the hospital.

You didn't feel a disconnect. I was able to speak freely with [obstetrics physician] and in the comfort of my own office. I have a door, I was able to shut the door and just have the meeting during my lunch hour so it was perfect (P12, aged 41).

Saving gas money, parking money, and I hate driving so it was a huge emotional stress driving to Kingston every single time. My mental health was much better for not having to go at that time (P8, aged 31).

I didn't have to worry about either being off work or being on lunch or making sure I could leave work or whatever (P2, aged 35).

\section{Facilitating emotional support and building rapport with the physician}

Lastly, participants perceived that virtual care gave them easier access to emotional support, helping them to build rapport with their obstetric medicine physician.

Kingston's a far drive for me so when I was near the end, especially when you're heavily pregnant, I already had that emotional support and I could trust my doctor, so just being able to do a virtual visit was huge for me. It helped my husband not have to arrange his schedule for work and it helped 
Table 2 Travel time, number of virtual visits, and medical profiles of participants

\begin{tabular}{|c|c|c|c|c|c|c|c|}
\hline Patient & Age & $\begin{array}{l}\text { Two-way } \\
\text { travel } \\
\text { Distance }(\mathrm{km})\end{array}$ & $\begin{array}{l}\text { Two-way } \\
\text { travel time } \\
\text { (min) }\end{array}$ & $\begin{array}{l}\text { Number } \\
\text { of virtual } \\
\text { visits }\end{array}$ & Gravida-para/TPAL status & Pregnancy status & Medical conditions \\
\hline Patient 1 & 36 & 160 & 132 & 1 & G4T1A2L1 & Postpartum & $\begin{array}{l}\text { Pregnancy related pulmonary } \\
\text { embolism }\end{array}$ \\
\hline Patient 2 & 35 & 44.8 & 50 & 3 & G2T2 & Postpartum & Hypertension \\
\hline Patient 3 & 34 & 118 & 162 & 1 & $\mathrm{G} 2 \mathrm{P} 1 \mathrm{~A} 1$ & Postpartum & Gestational hypertension \\
\hline Patient 4 & 34 & 36.2 & 48 & 1 & G2 P2 & Postpartum & $\begin{array}{l}\text { Hypertension; gestational diabe- } \\
\text { tes; mental health disorder; }\end{array}$ \\
\hline Patient 5 & 34 & 7.4 & 14 & 3 & G1 P1 & Postpartum & $\begin{array}{l}\text { Preeclampsia; hypertension; iron } \\
\text { deficiency anemia }\end{array}$ \\
\hline Patient 6 & 34 & 145.4 & 108 & 2 & G2P3 (G1 was twins) & Postpartum & $\begin{array}{l}\text { Postpartum hypertension; tachy- } \\
\text { cardia; preeclampsia; }\end{array}$ \\
\hline Patient 7 & 32 & 6.6 & 12 & 2 & G3P2A1 & Postpartum & $\begin{array}{l}\text { Chronic hypertension; Bell's palsy; } \\
\text { proteinuria; }\end{array}$ \\
\hline Patient 8 & 31 & 6 & 10 & 1 & $\mathrm{G} 2 \mathrm{P} 2$ & Postpartum & $\begin{array}{l}\text { Hypertension, celiac disease, } \\
\text { thyroid nodularity; thrombocy- } \\
\text { topenia; }\end{array}$ \\
\hline Patient 9 & 28 & 55 & 64 & 3 & G1P0 & Antepartum & $\begin{array}{l}\text { Lymphadenopathy and spleno- } \\
\text { megaly NDY, chronic headache, } \\
\text { borderline high blood pressure, } \\
\text { overweight, Herpes Zoster (early } \\
\text { pregnancy), endometriosis }\end{array}$ \\
\hline Patient 10 & 28 & 160.2 & 108 & 1 & $\mathrm{G} 2 \mathrm{P} 2$ & Postpartum & $\begin{array}{l}\text { Pulmonary embolism, postpartum } \\
\text { anemia secondary to postpar- } \\
\text { tum hemorrhage; irritable bowel } \\
\text { syndrome, PTSD; }\end{array}$ \\
\hline Patient 11 & 22 & 56 & 64 & 1 & G1P1 & Postpartum & Episodic hypotension; arrhythmia \\
\hline Patient 12 & 41 & 30.6 & 44 & 2 & G2T0A1L0 & Antepartum & $\begin{array}{l}\text { Pre-existing/chronic hypertension; } \\
\text { iron deficiency anemia; }\end{array}$ \\
\hline Patient 13 & 37 & 19.2 & 30 & 1 & G2T1P1A0L1 & Postpartum & Allergic rhinitis, asthma, acid reflux \\
\hline Patient 14 & 40 & 6.4 & 16 & 4 & G4P2A2 & Postpartum & $\begin{array}{l}\text { Type } 1 \text { diabetes; postpartum } \\
\text { hypertension }\end{array}$ \\
\hline Patient 15 & 36 & 168 & 130 & 1 & G4T1A2L1 & Postpartum & Pulmonary embolism \\
\hline
\end{tabular}

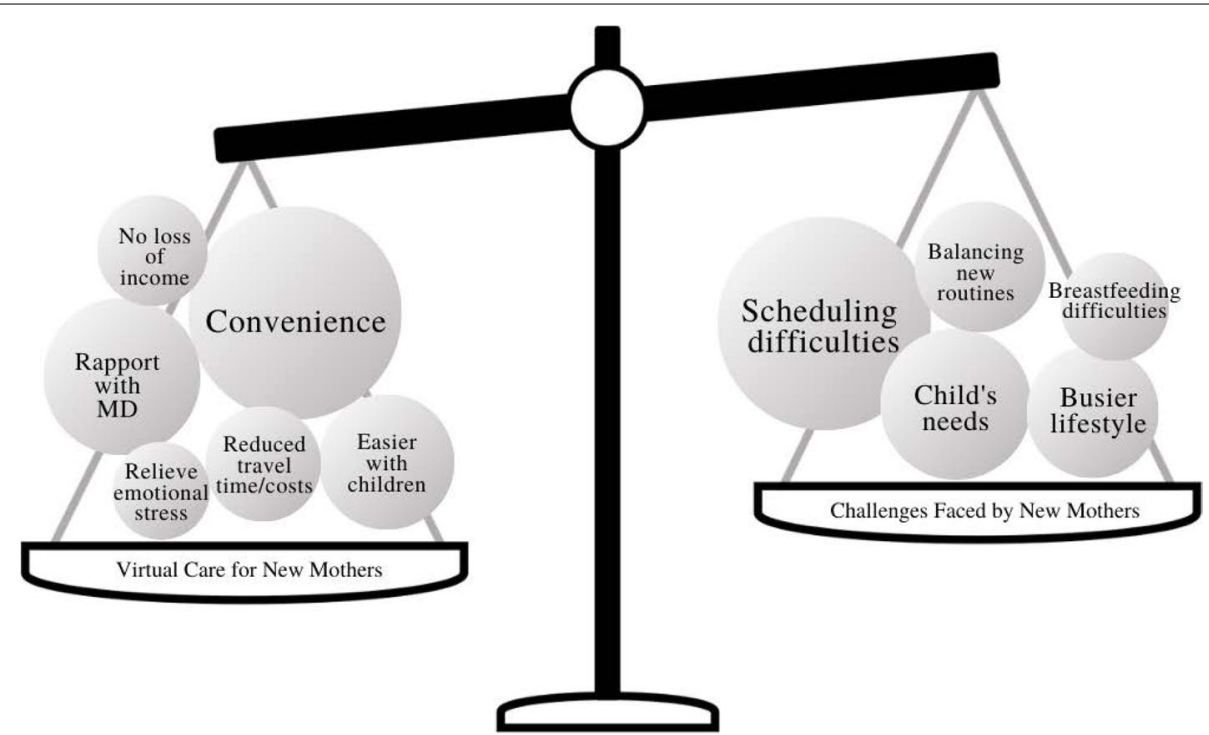

Fig. 1 Two broad umbrella themes that emerged through second stage coding 


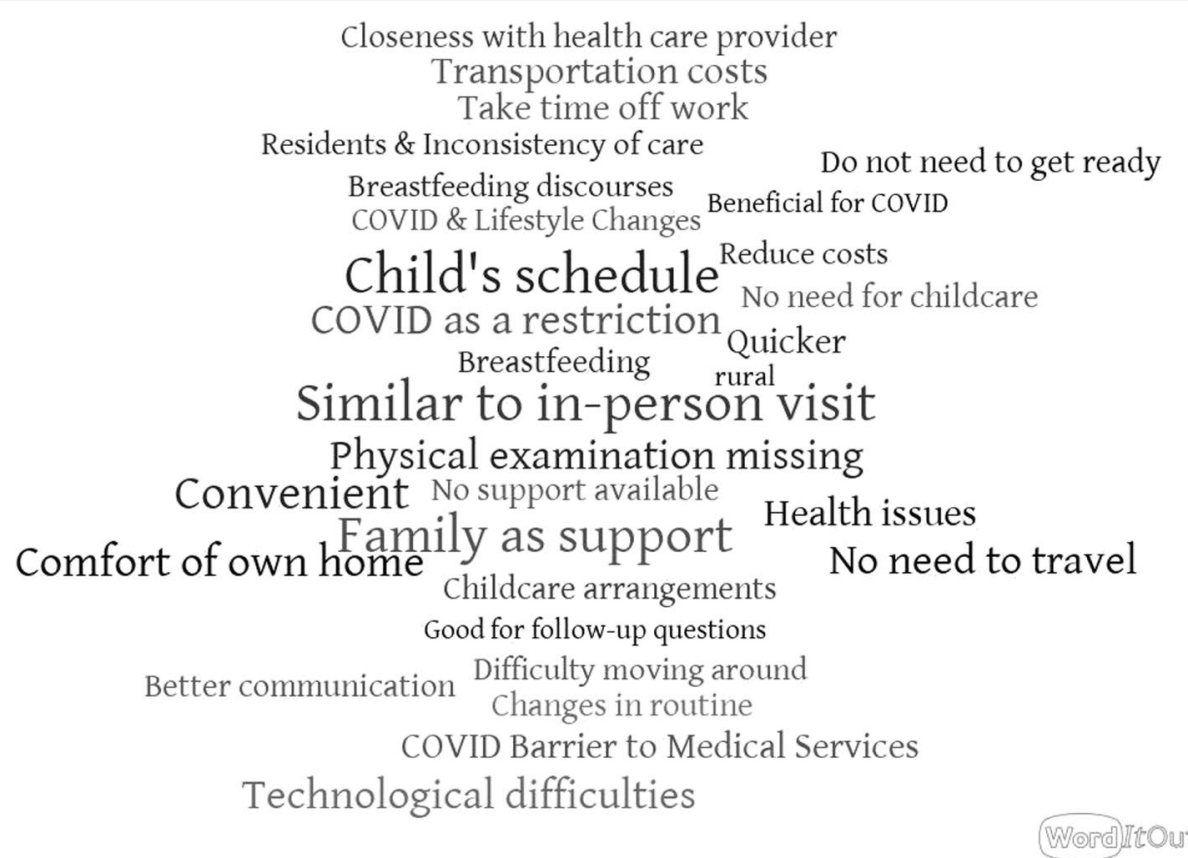

Fig. 2 Word map of the 30 most frequently occurring themes in the study. The presented themes in this word map were referenced at least 2 times

me still stay reassured that everything was going to be fine (P8, aged 31).

As a mom, you have so many questions about is this normal, is this working right and you don't really know who to turn to with those questions. I'm quite a worrier so I worry about a lot of things. It's just nice to have that. It's a little less formal. You don't feel like you're taking up a lot of time. You don't have to book an appointment just to get one quick question answered (P1, aged 36).

\section{Challenging Aspects of Using Virtual Care}

Few participants spoke to the negative aspects of using virtual care. While many of the participants in this study did not experience technological difficulties, some perceived that poor internet connectivity, audio issues, and technology could serve as barrier for some patients, especially those in rural communities or those who do not have access to high-speed internet:

For me it's easy to navigate. If it was my parents it would be a nightmare. They're...needs to be seen in person. It's just not gonna happen. Accessibility, we're in a rural area and we don't really even have high speed internet. We're lucky we're still not dialup...My parents live in a place where it's hard to even get any internet. They live five minutes down the road and you have to pay for one of those special satellite things to come or get the tower in order to even get internet (P8, aged 31).

I come from an area, if you drive five minutes down the road, you can't even really get access [inaudible]. It's terrible. (P12, aged 41)

\section{Discussion}

The purpose of this study was to understand the perceptions of new mothers (obstetric patients) using virtual care for postnatal follow-up care. The data suggests that virtual visits were considered a convenient, low-barrier, and accessible modality for healthcare delivery for postnatal follow-up care. In the context of being a new mother, participants felt that virtual visits were able to address many challenges unique to this population, such as scheduling difficulties, needing to arrange for childcare, and time constraints due to busier routines. These findings are consistent with previous literature, where patients found virtual care to be convenient, time-saving, and accessible for patients with unique physical impairments $[15,26]$.

\section{Benefits of virtual care as a means towards patient compliance to follow-up care Sub-Theme 1: Increased comfort and convenience}

While there have been relatively limited studies examining the use of virtual care in the form of video 
conferencing for maternal healthcare in the postpartum period, our results are consistent with previous literature examining patient satisfaction with virtual obstetric care in the prenatal period [27]. Virtual visits have been found not only be convenient, but to uphold the same level of rapport in the patient-provider encounter. In a U.S.based cross-sectional survey examining patient's preferences for telehealth visits, almost $1 / 3^{\text {rd }}$ of participants expressed a preference for telehealth, and over $1 / 2$ of participants rated telehealth to be just as good as traditional in person care [28]. Likewise, our participants expressed that virtual visits were comparable or even better than in-person visits where follow-up do not necessitate being seen for a physical examination.

The participants in this study also expressed enthusiasm for the use of virtual visits in the follow-up care context, where the convenience of being able to see a provider at home for a simple follow-up appointment was significant in terms of comfort, convenience, and costs. In our study, several participants recalled that they had forgotten to attend their appointments. However, all felt inclined to use virtual visits once they were reminded to do so through phone call by the clinic secretary due to its perceived ease of use. This is consistent with literature examining patient experiences with telehealth for follow-up care specifically, and further supports the utility of virtual care for increasing compliance to postnatal follow-up healthcare appointments [29].

In other studies of the use of telemedicine in early discharge from childbirth, patients also reported feeling confident with the ease of the technology and did not perceive a threat to their privacy or personal information. In a pilot project based in Sweden, patients reported feeling confident that their concerns and questions were addressed to the same degree through video conferencing and that communication with their provider was not compromised [30]. This may be attributed to the fact that younger mothers may already incorporate technology in their daily lives [31]. Resultantly, young mothers may more positively take up virtual care in comparison to other patient populations or age groups.

\section{Subtheme 2: Relieving stress associated with in-person care}

Our participants also expressed how virtual visit was able to address barriers related to financial constraints, distance, travel time, and arranging time off work, which is consistent with previous literature examining the benefits of virtual care visits in primary care settings. In our study, virtual care was found to be highly favored amongst participants living out of the city and/ or in rural towns, as they did not have to spend time, costs, and energy to attend to the hospital. Virtual care was also found to be useful for women with multiple children in our study, as they were not required to make extra childcare arrangements, find caretakers, and spend associated costs. Other participants perceived that virtual care would not interrupt their source of income as they were able to conduct the virtual session otherwise. This was particularly relevant throughout the ongoing COVID-19 pandemic, as patients were not permitted to bring other children to in-person visits in order to prevent unwanted exposure. These findings are also consistent with other studies exploring the use of virtual care in other patient populations, which support its use in alleviating the aforementioned barriers related to accessing in-person healthcare services $[13,15,26,32]$.

Overall, the perceived benefits of virtual care could provide insight into ways to increase patient compliance to post-natal follow-up care. In another study conducted by researchers at the Kingston Health Sciences Centre, it was found that increasing distance from the hospital was significantly associated with poorer attendance at follow-up visits. To a less significant degree, it was also found that poorer follow up was associated with patients with a greater number of living children and women with no educational certificate, diploma, or degree [10].

\section{Subtheme 3: Facilitating emotional support and rapport with the physician}

Rapport and trust is important to building strong relationships between physicians and patients. Rapport is also an important part of providing compassionate care and emotional support, particularly as new mothers experience physiological, emotional, and domestic changes related to childbirth [33]. However, it may be more difficult to establish rapport and provide support without in-person interactions. Most of the available literature on virtual care has focused on patient experiences more generally, and less on examining patient-physician rapport in virtual care.

Our findings illustrate the significance of building strong rapport between patients and their obstetric physician. Participants felt they were able to feel "calm" and supported by their obstetric physicians because they were able to contact their physician at their convenience when they had a question. Thus, participants perceived that virtual care by means of video conferencing was particularly useful as they were able to receive affirmation by seeing the gestures and demeanor of their physician. In this way, participants were able to build trust and rapport with their physician despite receiving care remotely. Given the significance of building rapport and trust for obstetric patients, physicians and patients would benefit from more research on ways to build rapport through 
video-based virtual care platforms to improve long-term compliance and patient-centered care.

\section{Barriers of virtual care and the need to consider social factors and determinants of health}

Virtual care appears to be an important modality for increasing compliance to post-natal follow-up care. This is likely due to the fact that virtual care addresses the various social and environmental factors that intersect to impact health care access. Income, geography, and educational background are commonly understood as some of the most significant social determinants of health $[18,34,35]$. Compounded by domestic tasks and expectations, women may feel overwhelmed, overburdened, or disinclined to attend postnatal follow-up clinics [36]. Since virtual care can be conducted at a place comfortable for the patient and at their own schedule, it may become easier for women to attend to attend regular follow-up visits for maternal health monitoring. As a result, virtual care should be positioned not only as a tool to facilitate compliance in follow-up, but as a tool to evaluate the various social and environmental determinants that may encourage or deter patients from attending follow-up clinics.

Our study did allude to one major limitation of virtual visits, in that the internet connection can vary considerably between patients and pose a potential barrier for conducting virtual care appointments [37]. This limitation can be exacerbated by various socioeconomic factors such as rurality or financial constraints. Patients who are unable to afford a highspeed internet connection or those who live in rural areas with poor connectivity may find themselves limited in their ability to access virtual care appointments [26]. This finding is consistent with previous literature indicating that virtual modalities for healthcare delivery in primary care can be limited when it comes to connection issues [38-42].

\section{Limitations of the study}

This study was limited by the relative homogeneity of the sample. As many of the participants were white/Caucasian, married, Canadian-born, middle-class, and well educated women, the perceived positive and negative aspects of virtual visits could be different if a more heterogenous sample was interviewed. For example, as Canada is an immigrant-dense country, language barriers, especially if virtual visits are not offered in multiple languages, could potentially be a limiting factor. However, participants were highly satisfied with the virtual visit platform for postnatal follow-up appointments, and the comfort and convenience it provides to participants are relevant across patient demographics. The research team also acknowledges that the sample size for this study is relatively small. This could be attributed to a large number of patients who had declined to participate as well as the research team's decision to take an ethnographic approach to the data in order to draw out rich details from the participants. The research team also acknowledges that a potential source of selection bias is that the obstetric medicine physicians on the team conducting the virtual visits asked patients about their interest in study participation. Those study team members invited interested patients to participate in the study. There is also potential selection bias as only some women from the clinic participated in the virtual visits. However, this form of purposive sampling was necessary because 1) there was only a small sample available, and 2) because virtual care was relatively new at KHSC at the time of the study, not all patients received it during the study period.

\section{Future directions and conclusion}

While this study showed that new mothers found virtual visits to be a suitable modality of healthcare delivery for postnatal follow-up, our interviews alluded to a variety of challenges that new mothers experience that may differentially impact their ability to seek care. Therefore, future studies should investigate barriers to accessing in-person healthcare services for new mothers in order to better understand the unique determinants and barriers of this patient population. Intersectionality theory would serve well to illuminate the connections between the social determinants of health and barriers to virtual care. Furthermore, virtual care has the potential to significantly shift the landscape of healthcare delivery in the COVID era, and further research should specifically examine patient experiences of virtual visit in relation to the ongoing pandemic.

In conclusion, qualitative interviews with new mothers who have used virtual care in the form of virtual visit for postnatal follow-up appointment visits revealed high satisfaction with virtual care, emphasizing benefits in terms of comfort, convenience, communication, socioeconomic factors, and the ease of technology use. In the follow-up care context, our findings suggest that virtual care increases accessibility and ease of follow-up care for patients with unique barriers to accessing healthcare services. Such a lens not only addresses the struggle of long-term patient compliance to maternal health care, but will also shed light on how to make obstetric care more equitable. Future directions should seek to examine the barriers to accessing in-person healthcare services unique to new mothers and examining the applicability of virtual visits for 
this patient population in the context of the ongoing COVID-19 pandemic.

\section{Supplementary Information}

The online version contains supplementary material available at https://doi. org/10.1186/s12884-021-03999-9.

\section{Additional file 1.}

\section{Acknowledgements}

The study team would like to acknowledge and thank all the participants for sharing their stories for this study.

\section{Authors' contributions}

M.S. and S.C were involved in recruitment, data collection, data analysis, and the writing of the manuscripts. R.A. was responsible for the conception of the study. L.N. and S.S were involved with recruitment and conceptualizing the recruitment strategy. All authors reviewed all iterations of the manuscript. The authors read and approved the final manuscript.

\section{Funding}

The author(s) disclosed receipt of the following financial support for the research, authorship, and/or publication of this article. This work was supported by the PSI Foundation under Grant \#19-31.

\section{Availability of data and materials}

As per the conditions with the Queen's University's Health Sciences Research Ethics Board, the datasets generated during and/or analysed during the current study are not publicly available because of the chance of identification due to a small sample size. However, the data can be made available from the corresponding author on reasonable request.

\section{Declarations}

\section{Ethics approval and consent to participate}

Ethics approval was obtained from the Queen's University Health Sciences Review Ethics Board (\# 6026701). Verbal informed consent was obtained from the patient(s) for their anonymized information to be published in this article. All methods were carried out in accordance with relevant guidelines and regulations.

\section{Consent for publication}

Not applicable.

\section{Competing interests}

RA reports research grants from CIHR, PSI Foundation, Ontario, Canada Health Infoway, Department of Medicine, Queen's University, Southeastern Ontario Academic Medical Organization, Kingston General Hospital Research Institute.

\section{Author details}

${ }^{1}$ School of Medicine, Queen's University, Kingston, ON, Canada. ${ }^{2}$ Department of Medicine, Queen's University, Kingston, ON, Canada.

Received: 7 January 2021 Accepted: 12 July 2021

Published online: 07 August 2021

\section{References}

1. Katsi V, Skalis G, Vamvakou G, Tousoulis D, Makris T. Postpartum Hypertension. Curr Hypertens Rep. 2020;22(8):58.

2. Ma RCW, Schmidt MI, Tam WH, Mclntyre HD, Catalano PM. Clinical management of pregnancy in the obese mother: before conception, during pregnancy, and post partum. Lancet Diabetes Endocrinol. 2016:4(12):1037-49.

3. ACOG. Committe opinion: Optimizing Postpartum care. In: Presidential Task Force on Redefining the Postpartum Visit Committee on Obstretric
Practice. vol. 131. Washington, DC: The American College of Obstetricians and Gynecologists; 2018. pp. e140-e150.

4. Fraser A, Nelson SM, Macdonald-Wallis C, Cherry L, Butler E, Sattar N, Lawlor DA. Associations of pregnancy complications with calculated cardiovascular disease risk and cardiovascular risk factors in middle age: the Avon Longitudinal Study of Parents and Children. Circulation (New York, NY). 2012;125(11):1367-80.

5. Cusimano MC, Pudwell J, Roddy M. Cho C-KJ, Smith GN: The maternal health clinic: an initiative for cardiovascular risk identification in women with pregnancy-related complications. Am J Obstet Gynecol. 2014;210(5):438.e431-438.e439.

6. Rezaei N, Tavalaee Z, Sayehmiri K, Sharifi N, Daliri S. The relationship between quality of life and methods of delivery: A systematic review and meta-analysis. Electron Physician. 2018;10(4):6596-607.

7. Martinez-Galiano JM, Hernandez-Martinez A, Rodriguez-Almagro J, Delgado-Rodriguez M, Rubio-Alvarez A, Gomez-Salgado J. Women's Quality of Life at 6 Weeks Postpartum: Influence of the Discomfort Present in the Puerperium. Int J Environ Res Public Health. 2019;16(2):253.

8. Kohler S, Sidney Annerstedt K, Diwan V, Lindholm L, Randive B, Vora K, De Costa A. Postpartum quality of life in Indian women after vaginal birth and cesarean section: a pilot study using the EQ-5D-5L descriptive system. BMC Pregnancy Childbirth. 2018;18(1):427.

9. Bai G, Korfage IJ, Mautner E, Raat H. Determinants of Maternal HealthRelated Quality of Life after Childbirth: The Generation R Study. Int J Environ Res Public Health. 2019;16(18):3231.

10. Nowik CMMDMPA, Pudwell JMPH, Smith GNMDPF. Evaluating the Postpartum Maternal Health Clinic: How Patient Characteristics Predict Follow-Up. J Obstet Gynaecol Can. 2016;38(10):930-5.

11. Kornelsen J. Rural women's experiences of maternity care, implications for policy and practice. Status of Women Canada; 2005.

12. Call VR, Erickson LD, Dailey NK, Hicken BL, Rupper R, Yorgason JB, Bair B. Attitudes Toward Telemedicine in Urban, Rural, and Highly Rural Communities. Telemed J E Health. 2015;21(8):644-51.

13. Hollander JE, Carr BG. Virtually Perfect? Telemedicine for Covid-19. N Engl J Med. 2020;382(18):1679-81.

14. Lougheed T. Time to embrace the promise of virtual health care. Can Med Assoc J. 2019;191(11):E320-1.

15. Appireddy R, Khan S, Leaver C, Martin C, Jin A, Durafourt BA, Archer SL. Home Virtual Visits for Outpatient Follow-Up Stroke Care: Cross-Sectional Study. J Med Internet Res. 2019;21(10):e13734.

16. Canadian Medical Association. Virtual Care in Canada: Discussion Paper. In: CMA Health Summit [Internet]: 2019.

17. CSDH. Final report of the Commission on Social Determinants of Health. In: Closing the gap in a generation-Health equity through action on the social determinants of health. Geneva: World Health Organization; 2008.

18. Bambra C, Gibson M, Sowden A, Wright K, Whitehead M, Petticrew M. Tackling the wider social determinants of health and health inequalities: evidence from systematic reviews. J Epidemiol Community Health (1979). 2010;64(4):284-91.

19. Wilson-Mitchell K, Rummens J. Perinatal Outcomes of Uninsured Immigrant, Refugee and Migrant Mothers and Newborns Living in Toronto, Canada. Int J Environ Res Public Health. 2013;10(6):2198-213.

20. Crowe S, Cresswell K, Robertson A, Huby G, Avery A, Sheikh A. The case study approach. BMC Med Res Methodol. 2011;11(1):100-100.

21. Yin RK, Campbell DT. Case study research and applications: design and methods, Sixth edition. edn. Thousand Oaks: SAGE Publications; 2018.

22. Munhall PL. Perception. In: The SAGE Encyclopedia of Qualitative Research Methods. Given LM (Editor). Thousand Oaks: SAGE Publications; 2008. p. 607.

23. Kvale S, Brinkmann S: InterViews: Learning the craft of qualitative research interviewing. Thousand Oaks: SAGE Publications; 2008.

24. Ontario Telemedicine Network. Virtual Care Organizations [Internet]. https://www-origin.otn.ca/providers/ohts/.

25. Smith JA. Qualitative psychology: a practical guide to research methods. SAGE Publications; 2003.

26. Chan S, O'Riordan A, Appireddy R. Exploring the determinants and experiences of senior stroke patients with virtual care. Can J Neurol Sci. 2021;48(1):87-93.

27. Pflugeisen BM, Mou J. Patient Satisfaction with Virtual Obstetric Care. Matern Child Health J. 2017;21(7):1544-51. 
28. Polinski JM, Barker T, Gagliano N, Sussman A, Brennan TA, Shrank WH. Patients' Satisfaction with and Preference for Telehealth Visits. J Gen Intern Med. 2015;31(3):269-75.

29. Donelan KBE, Sossong S, Michael C, Estrada JJ, Cohen AB, Wozniak J, Schwamm LH. Patient and clinician experiences with telehealth for patient follow-up care. Am J Manag Care. 2019;25(1):40-4.

30. Lindberg I, Christensson K, Öhrling K. Parents' experiences of using videoconferencing as a support in early discharge after childbirth. Midwifery. 2009;25(4):357-65.

31. Corey S, Meghan G. Generation Z: A Century in the Making. London: Taylor and Francis; 2018.

32. Dewar S, Lee PG, Suh TT, Min L. Uptake of Virtual Visits in A Geriatric Primary Care Clinic During the COVID-19 Pandemic. J Am Geriatr Soc. 2020;68(7):1392-4.

33. Levine $\mathrm{OH}$, McGillion M, Levine M. Virtual Cancer Care During the COVID-19 Pandemic and Beyond: A Call for Evaluation. JMIR Cancer. 2020;6(2):e24222-e24222.

34. Bates LM, Hankivsky O, Springer KW. Gender and health inequities: A comment on the Final Report of the WHO Commission on the Social Determinants of Health. Soc Sci Med. 2009:69(7):1002-4.

35. Jackson SF, Birn A, Fawcett SB, Poland B, Schults JA. Synergy for health equity: integrating health promotion and social determinants of health approaches in and beyond the Americas. Rev Panam Salud Publica. 2013:34(6):473-80.
36. Spitzer DL. Engendering Health Disparities. Can J Public Health Rev Can Sante'e Publique. 2005;96:596-s96.

37. Crawford A, Serhal E. Digital Health Equity and COVID-19: The Innovation Curve Cannot Reinforce the Social Gradient of Health. J Med Internet Res. 2020;22(6):e19361.

38. Powell RE, Henstenburg JM, Cooper G, Hollander JE, Rising KL. Patient Perceptions of Telehealth Primary Care Video Visits. Ann Fam Med. 2017;15(3):225-9

39. Kruse CS, Karem P, Shifflett K, Vegi L, Ravi K, Brooks M. Evaluating barriers to adopting telemedicine worldwide: A systematic review. J Telemed Telecare. 2016;24(1):4-12.

40. Mehta SJ. Telemedicine's Potential Ethical Pitfalls. Virtual Mentor. 2014;16(12):1014-7.

41. West DM, Miller EA. The Digital Divide in Public E-Health: Barriers to Accessibility and Privacy in State Health Department Websites. J Health Care Poor Underserved. 2006;17(3):652-67.

42. Vogel L. Canada has long way to go on virtual care. CMAJ. 2020;192(9):E227-8.

\section{Publisher's Note}

Springer Nature remains neutral with regard to jurisdictional claims in published maps and institutional affiliations.
Ready to submit your research? Choose BMC and benefit from:

- fast, convenient online submission

- thorough peer review by experienced researchers in your field

- rapid publication on acceptance

- support for research data, including large and complex data types

- gold Open Access which fosters wider collaboration and increased citations

- maximum visibility for your research: over $100 \mathrm{M}$ website views per year

At $\mathrm{BMC}$, research is always in progress.

Learn more biomedcentral.com/submissions 